\title{
Wechsler Preschool and Primary Scale of Intelligence
}

National Cancer Institute

\section{Source}

National Cancer Institute. Wechsler Preschool and Primary Scale of Intelligence. NCI

Thesaurus. Code C86974.

An intelligence test published by Harcourt Assessment and designed for children ages 2 years 6 months to 7 years 3 months. It provides subtest and composite scores that represent intellectual functioning in verbal and performance cognitive domains, and provides a composite score that represents a child's general intellectual ability. 